\title{
An increase in elastogenic components in the placental villi of women with chronic venous disease during pregnancy is associated with decreased EGFL7 expression level
}

\author{
MIGUEL A. ORTEGA ${ }^{1-3}$, ÁNGEL ASÚNSOLO ${ }^{2,4}$, OSCAR FRAILE-MARTÍNEZ ${ }^{1}$, FELIPE SAINZ ${ }^{3-5}$, \\ MIGUEL A. SAEZ ${ }^{1,3,6}$, CORAL BRAVO ${ }^{3,4,7}$, JUAN A. DE LEÓN-LUIS ${ }^{7-9}$, MIGUEL A. ALVAREZ-MON $^{1,2}$, \\ SANTIAGO COCA ${ }^{1-3}$, MELCHOR ÁLVAREZ-MON $^{1-3,10^{*}}$, JULIA BUJÁN $^{1-3 *}$ and NATALIO GARCÍA-HONDUVILLA ${ }^{1-3 *}$ \\ ${ }^{1}$ Department of Medicine and Medical Specialties, Faculty of Medicine and Health Sciences, University of Alcalá, \\ Alcalá de Henares, 28801 Madrid; ${ }^{2}$ Ramón y Cajal Institute of Healthcare Research, 28034 Madrid; ${ }^{3}$ University Center for \\ The Defense of Madrid, 28047 Madrid; ${ }^{4}$ Department of Surgery, Medical and Social Sciences, Faculty of Medicine and \\ Health Sciences, University of Alcalá, Alcalá de Henares, 28801 Madrid; ${ }^{5}$ Angiology and Vascular Surgery Service; \\ ${ }^{6}$ Pathological Anatomy Service; ${ }^{7}$ Service of Gynecology and Obstetrics, Section of Fetal Maternal Medicine, \\ Central University Hospital of Defence-University of Alcalá, 28047 Madrid; ${ }^{8}$ Fetal Medicine Unit, Maternal and \\ Child Health and Development Network, Department of Obstetrics and Gynecology, Gregorio Marañón Hospital; \\ ${ }^{9}$ Department of Obstetrics and Gynecology, Complutense University of Madrid, 28040 Madrid; \\ ${ }^{10}$ Immune System Diseases-Rheumatology and Oncology Service, University Hospital Príncipe de Asturias, Center for \\ Biomedical Research Network for Liver and Digestive Diseases (CIBEREHD), Alcalá de Henares, 28801 Madrid, Spain
}

Received November 17, 2020; Accepted February 24, 2021

DOI: $10.3892 / \mathrm{mmr} .2021 .12195$

\begin{abstract}
Chronic venous disease (CVD) is the response to a series of hemodynamic changes in the venous system and the onset of this disease is often triggered by pregnancy. Placental tissue is particularly sensitive to the characteristic changes which occurs in venous hypertension. In this regard, changes in the extracellular matrix (ECM), that occur to adapt to this situation, are fundamental to controlling elastogenesis. Therefore, the aim of the present study was to analyze the changes that occur in the mRNA and protein expression level of proteins related to elastogenesis in the placental villi of women diagnosed with CVD, in the third trimester of pregnancy. An observational, analytical and prospective cohort study was conducted, in which the placenta from 62 women with CVD were compared with that in placenta from 52 women without a diagnosis of CVD. Gene and protein expression levels were analyzed using reverse transcription-quantitative PCR and
\end{abstract}

Correspondence to: Professor Julia Buján, Department of Medicine and Medical Specialties, Faculty of Medicine and Health Sciences, University of Alcalá, Campus Universitario-C/19, Av. de Madrid, Km 33,600 Alcalá de Henares, 28801 Madrid, Spain

E-mail: mjulia.bujan@uah.es

${ }^{*}$ Contributed equally

Key words: chronic venous disease, pregnancy, extracellular matrix, elastogenesis, EGFL7 immunohistochemistry, respectively. The results showed a significant decrease in the gene and protein expression level of EGFL7 in the placental villi of women with CVD. By contrast, significant increases in the gene and protein expression level of ECM-related proteins, such as tropoelastin, fibulin 4, fibrillin 1 and members of the lysyl oxidase family (LOX and LOXL-1) were also found in the placental villi of women with CVD. To the best of our knowledge, the results from the present study showed for the first time that CVD during pregnancy was associated with changes in the mRNA and protein expression level in essential components of the EGFL7-modulated elastogenesis process in placental villi.

\section{Introduction}

Pregnancy produces important changes in the tissues and homeostasis of women and the most important are those related to the cardiovascular system, such as an increase in blood volume and alterations in systemic vascular resistance (1-3). Numerous studies have shown how the venous system is affected during pregnancy, particularly with the development of chronic venous disease (CVD), which is clinically diagnosed by the presence of varicose veins (2-4). As CVD progresses, there is a simultaneous decrease in blood flow velocity (5), an increase in leg vein diameter (6) and valve closure time (7). These hemodynamic alterations during pregnancy can lead to venous hypertension and affect venous return, with the appearance of varicose veins being the most important clinical manifestation (8). Age, family history, occupation and diet are other important risk factors, that have been associated with the appearance of this condition (9). 
Preeclampsia is one of the most important vascular pathologies associated with pregnancy. It is a vascular alteration characterized by systemic hypertension, that can seriously compromise the health of the mother and the fetus, and in which important changes in placental tissue also occurs (10). Gestational venous hypertension is a lower-risk condition for both the mother and child, and our previous studies revealed the association between CVD during pregnancy, increased cell damage in the placental villi of those women and increased cellular hypoxia $(3,11)$. In this regard, it is important to determine how the extracellular matrix (ECM) behaves in these placental villi to reveal the consequences of CVD during pregnancy. Proper functioning of the ECM is key to the development of the placenta from the very earliest stages (12). The process of elastogenesis is fundamental for correct embryonic development (13). The EGF-like domain-containing protein 7 (EGFL7) plays a key role in the ECM (14). Lelièvre et al (15) demonstrated that EGFL7 regulated the catalytic activity of different components of elastic fiber assembly, which affected ECM homeostasis. Alterations in the composition of the ECM are present in a wide variety of pathologies associated with pregnancy, such as preeclampsia and gestational trophoblastic diseases (16). Similarly, the placenta of patients with CVD during pregnancy was found to have significant alterations in the composition of the ECM, such as in the collagen fibers or in the calcifications of the placental villi (17-19).

Therefore, the aim of the present study was to analyze the gene and protein expression level of EGFL7 and the components of the elastic fibers of the ECM [tropoelastin (TE), fibulin 4 (FBLN-4), fibrillin 1 (FBN-1), lysyl oxidase (LOX) and lysyl oxidase-like 1 (LOXL-1)] in the placental villi of women with CVD during pregnancy.

\section{Materials and methods}

Study design. An observational, analytical and prospective study was performed and included 114 women in the third trimester of pregnancy (32 weeks). From these, 62 women were clinically diagnosed with CVD according to CEAP classification (20), with a median age of 33 years [interquartile range (IQR), 22-40 years] and a median gestational age of 40.5 weeks (IQR, 39-41.5 weeks). Simultaneously, 52 controls without a history of CVD [healthy controls (HC)] were also included, with a median age of 34 years (IQR, 27-41 years) and a median gestational age of 41 weeks (IQR, 39-42 weeks). The present study was conducted according to the basic ethical principles of autonomy, beneficence, non-maleficence and distributive justice. The development of the research followed the regulations of Good Clinical Practice, as well as the principles set forth in the last Declaration of Helsinki (2013) and the Oviedo Convention (1997). Patients were informed prior to enrolment, and each participant provided their corresponding written consent. The current study was approved by the Clinical Research Ethics Committee of the Central University Hospital of Defence-University of Alcalá (37/17). During the third trimester consultation, the clinical history was recorded, a general physical examination was performed and lower limb ultrasounds were conducted using an Eco-Doppler (Portable M-Turbo Eco-Doppler; SonoSite, Inc.) at $7.5 \mathrm{MHz}$.
The inclusion criteria were defined as women over 18 years of age, with clinical evidence of lower limb venous insufficiency (VI) in the third trimester, according to Clinical-Etiology-Anatomy-Pathophysiology classification $(\geq 1)$ (20). The exclusion criteria included women previously diagnosed with diabetes mellitus, gestational diabetes mellitus or other endocrine diseases; high blood pressure; autoimmune diseases; active infectious diseases; venous malformations; heart, kidney and lung insufficiency; preeclampsia and/or HELLP [an acronym for hemolysis $(\mathrm{H})$, elevated liver enzymes (EL) and a low platelet count (LP)] syndrome; known causes of intrauterine growth restrictions; body mass index $\geq 25$; toxicological habits [tobacco ( $\geq 1$ cigarette a day), alcohol ( $\geq 1$ unit a day) or drugs (e.g., cannabis, heroin, cocaine, amphetamines)]; existence of pathological injuries, such as placental infarction, avascular villi, delayed villi maturation or chronic villitis; as well as the appearance of any exclusion criteria in the following months (until delivery); and previous evidence of CVD. There were no significant differences between the groups regarding the number of previous pregnancies: $33(53.2 \%)$ for women with CVD and 19 (36.5\%) for women in the HC group (Table SI). There were also no significant differences in the clinical characteristics between the CVD and HC groups (gestational age, c-section delivery, previous pregnancies, previous abortions, regular menstrual cycles and type of profession-sedentary, Table SI).

Placental samples. Placental biopsies were collected once they were expelled after delivery. In all cases, 5 placental fragments were obtained in all cases using a scalpel to ensure that the samples included various cotyledons. These placental pieces were added to two different sterile tubes: One containing Minimum Essential Medium (MEM; Thermo Fisher Scientific, Inc.) with $1 \%$ antibiotic/antimycotic (Streptomycin, Amphotericin B and Penicillin) (Thermo Fisher Scientific, Inc.) and another with RNAlater ${ }^{\circledR}$ (Ambion; Thermo Fisher Scientific, Inc.) solution. The samples were processed in a class II laminar flow hood (Telstar AV 30/70 Müller $220 \mathrm{~V}$ $50 \mathrm{MHz}$; Telstar; Azbil Corporation) in a sterile environment. Preserved samples were stored in $1 \mathrm{ml}$ RNAlater ${ }^{\circledR}$ at $-80^{\circ} \mathrm{C}$ until they were processed for gene expression analysis. Conserved MEM placentas were used for histological and immunodetection studies.

The samples stored in MEM were washed and rehydrated five times in MEM without antibiotics to remove the blood cells, then they were cut into fragments $(2 \mathrm{~cm})$ and fixed in F13 (60\% ethanol, 20\% methanol, 7\% polyethylene glycol and $13 \%$ distilled water) following established protocols (20). The samples were then paraffin-embedded in blocks using moulds. After the paraffin had solidified, a HM 350 S rotation microtome (Thermo Fisher Scientific, Inc.) was used to obtain 5- $\mu \mathrm{m}$ thick sections, which were stretched in a hot water bath, then mounted on glass slides, previously treated with $10 \%$ polylysine, allowing for improved adhesion of the sections.

Gene expression studies using reverse transcription-quantitative $P C R(R T-q P C R)$. RNA was extracted according to the guanidinium thiocyanate-phenol-chloroform method $(21,22)$ and was used to analyze the mRNA expression levels of the genes of interest. 
RNA samples at a concentration of $50 \mathrm{ng} / \mu$ l were used to synthesize complementary DNA (cDNA) by reverse transcription; $4 \mu \mathrm{l}$ of each sample is mixed with $4 \mu \mathrm{l}$ of oligo-dT (15) $0.25 \mu \mathrm{g} / \mu \mathrm{l}$ solution (Thermo Fisher Scientific, Inc.), and incubated at $65^{\circ} \mathrm{C}$ for $10 \mathrm{~min}$ in a dry bath (AccuBlock, Labnet International Inc.), in order to denature the RNA. After this, the samples were placed on ice and $10 \mu \mathrm{l}$ per sample of a reverse transcription mix containing the following products was added for each sample: $2.8 \mu 1$ First Strand Buffer 5X (250 mM Tris- $\mathrm{HCl}$ and $\mathrm{pH} 8.3 ; 375 \mathrm{mM} \mathrm{KCl} ; 15 \mathrm{mM} \mathrm{MgCl}_{2}$ ) (Thermo Fisher Scientific, Inc.); $2 \mu 1$ of $10 \mathrm{mM}$ deoxyribonucleotides triphosphate; $2 \mu \mathrm{l}$ of $0.1 \mathrm{M}$ dithiothreitol; $1.7 \mu \mathrm{l}$ of DNase- and RNase-free water; $0.5 \mu 1$ of RNase inhibitor (RNase Out); $1 \mu 1$ of reverse transcriptase enzyme (all from Thermo Fisher Scientific, Inc.).

The RT process was carried out using a G-Storm GS1 thermal cycler (G-Storm Ltd.). The samples were incubated at $37^{\circ} \mathrm{C}$ for $1 \mathrm{~h}$ and $15 \mathrm{~min}$, to allow cDNA synthesis. The temperature was then increased to $70^{\circ} \mathrm{C}$ and maintained for $15 \mathrm{~min}$, thus causing the denaturation of the reverse transcriptase enzyme, and the temperature gradually decreased to $4^{\circ} \mathrm{C}$.

To verify the absence of genomic DNA contamination in the total RNA samples, a negative reverse transcription was performed in parallel in which the M-MLV RT enzyme is replaced by water free of DNases and RNases. The cDNA produced in RT was diluted 1:20 using water free of DNases and RNases and stored at $-20^{\circ} \mathrm{C}$ until use.

Specific primers for all the genes studied (Table SII) were designed de novo using the Primer-BLAST and AutoDimer online applications $(23,24)$. The constitutively expressed TATA-box binding protein (TBP) gene was used to as a control to normalize the results (25). The gene expression units are expressed as relative quantities of mRNA. RT-qPCR was performed on a StepOnePlus ${ }^{\mathrm{TM}}$ System (Applied Biosystems; Thermo Fisher Scientific, Inc.) and the relative standard curve method was used. The total reaction volume was $20 \mu \mathrm{l}$ and included: $5 \mu 1$ sample [mixed at 1:20 with $10 \mu 1 \mathrm{iQ}^{\mathrm{TM}} \mathrm{SYBR}^{\circledR}$ Green Supermix (Bio-Rad Laboratories, Inc.)], $1 \mu \mathrm{l}$ each forward and reverse primers, and $3 \mu \mathrm{l}$ DNase and RNase-free water, and added to a MicroAmp ${ }^{\circledR}$ 96-well plate (Applied Biosystems; Thermo Fisher Scientific, Inc.). The following thermocycling conditions were used: Initial denaturation at $95^{\circ} \mathrm{C}$ for $10 \mathrm{~min}$, denaturation at $95^{\circ} \mathrm{C}$ for $15 \mathrm{sec}$, annealing at variable temperatures depending on the melting temperature of each primer pair for $30 \mathrm{sec}$, and elongation at $72^{\circ} \mathrm{C}$ for $1 \mathrm{~min}$, for 40-45 cycles. Followed by a dissociation curve at $95^{\circ} \mathrm{C}$ for $15 \mathrm{sec}, 60^{\circ} \mathrm{C}$ for $1 \mathrm{~min}, 95^{\circ} \mathrm{C}$ for $15 \mathrm{sec}$, and $60^{\circ} \mathrm{C}$ for $15 \mathrm{sec}$. Fluorescence detection was performed at the end of each repeat cycle (amplification) and at each step of the dissociation curve. The data obtained from each gene was added in a standard curve made by serial dilutions of a mixture of the samples, that were included in each plate according to the constitutive expression of TBP (in accordance with the manufacturer's protocols). All tests were performed in duplicate in all samples of placenta tissue.

Immunohistochemistry studies for protein expression analysis. Immunohistochemical studies were performed on paraffin-embedded placental tissue samples. The antibody retrieval step was described in the protocol specifications
(Table SIII).The antigen/antibody reactions were detected using the avidin-biotin complex method, with avidin-peroxidase, as previously described (26). After incubation with the primary antibody (1 $\mathrm{h}$ and $30 \mathrm{~min}$; Table SIII), the samples were incubated with 3\% BSA Blocker (cat. no. 37525; Thermo Fisher Scientific, Inc.) and PBS overnight at $4^{\circ} \mathrm{C}$. Then, the cells were incubated with biotin-conjugated secondary antibody, diluted in PBS, for 90 min at room temperature (RT; Table SIII). The avidin-peroxidase conjugate ExtrAvidin ${ }^{\circledR}$-Peroxidase (Sigma-Aldrich; Merck KGaA) was used for $60 \mathrm{~min}$ at RT (1:200 dilution with PBS), then the protein expression level was determined using a chromogenic diaminobenzidine (DAB) substrate kit (cat. no. SK-4100; Maravai LifeSciences), which was prepared immediately before exposure $(5 \mathrm{ml}$ distilled water, two drops buffer, four drops DAB and two drops hydrogen peroxide). The signal was developed with the peroxidase chromogenic substrate for $15 \mathrm{~min}$ at RT; this technique allows for the detection of a brown stain. For the detection of each protein, sections of the same tissue were assigned as negative controls, substituting incubation with the primary antibody for a blocking solution (PBS). In all the tissues, the contrast was performed with Carazzi hematoxylin for 15 min at RT.

For each patient within the defined groups, 5 sections and 10 fields of view were randomly examined. The patients were described as positive when the marked mean area in the analyzed sample was $\geq 5 \%$ of the total, following the immunoreactive score (IRS) from Remmele and Schicketanz (27) and Cristóbal et al (28). Immunostaining in the tissue was assessed by two independent histologists, blinded to the outcome. In each sample, immunohistochemical staining was scored using the following scale: $0-1$, minimum staining $(\leq 25 \%)$; 2 , moderate staining (25-65\%); and 3-4, strong staining $(\geq 65-100 \%)$. Preparations were viewed using a Zeiss Axiophot optical microscope (Zeiss GmbH).

Orcein stain. Once the sections were dried, they were deparaffinized for 30 min in xylol at RT (PanReac AppliChem; Illinois Tool Works, Inc.) and subsequently rehydrated using a descending alcohol series until they were completely hydrated in distilled water. After rehydration, the sections of the samples were: i) Stained with alcoholic orcein for $30 \mathrm{~min}$ at RT, ii) washed with distilled water for $30 \mathrm{~min}$, iii) immersed in $96 \%$ alcohol for 5 min, iv) immersed in $100 \%$ alcohol for 15 min, v) discolored on the bottom with acid alcohol for 2-10 min, vi) washed with water for $10 \mathrm{~min}$, vii) stained with Carazzi hematoxylin for $20 \mathrm{~min}$ at $\mathrm{RT}$, viii) washed in running water for $10 \mathrm{~min}$, viiii) dehydrated in $96 \%$ alcohol for $5 \mathrm{~min}$, x) dehydrated in $100 \%$ alcohol for $5 \mathrm{~min}$, xi) submerged in xylol for $10 \mathrm{~min}$, and xii) mounted using Cytoseal ${ }^{\mathrm{TM}}$, which allows for the visualization of the elastic fibers with a brown color using an optical microscope (Zeiss $\mathrm{GmbH}$ ).

Statistical analysis. For the statistical analysis, the GraphPad Prism ${ }^{\circledR}$ v6.0 (GraphPad, Inc.) program was used. The Mann-Whitney U test was used to compare the 2 groups, and the data was expressed as the median and the IQR. For the categorical variables, Pearson's $\chi^{2}$ or Fisher's exact test was used. $\mathrm{P}<0.05$ was used to indicate a statistically significant difference. 

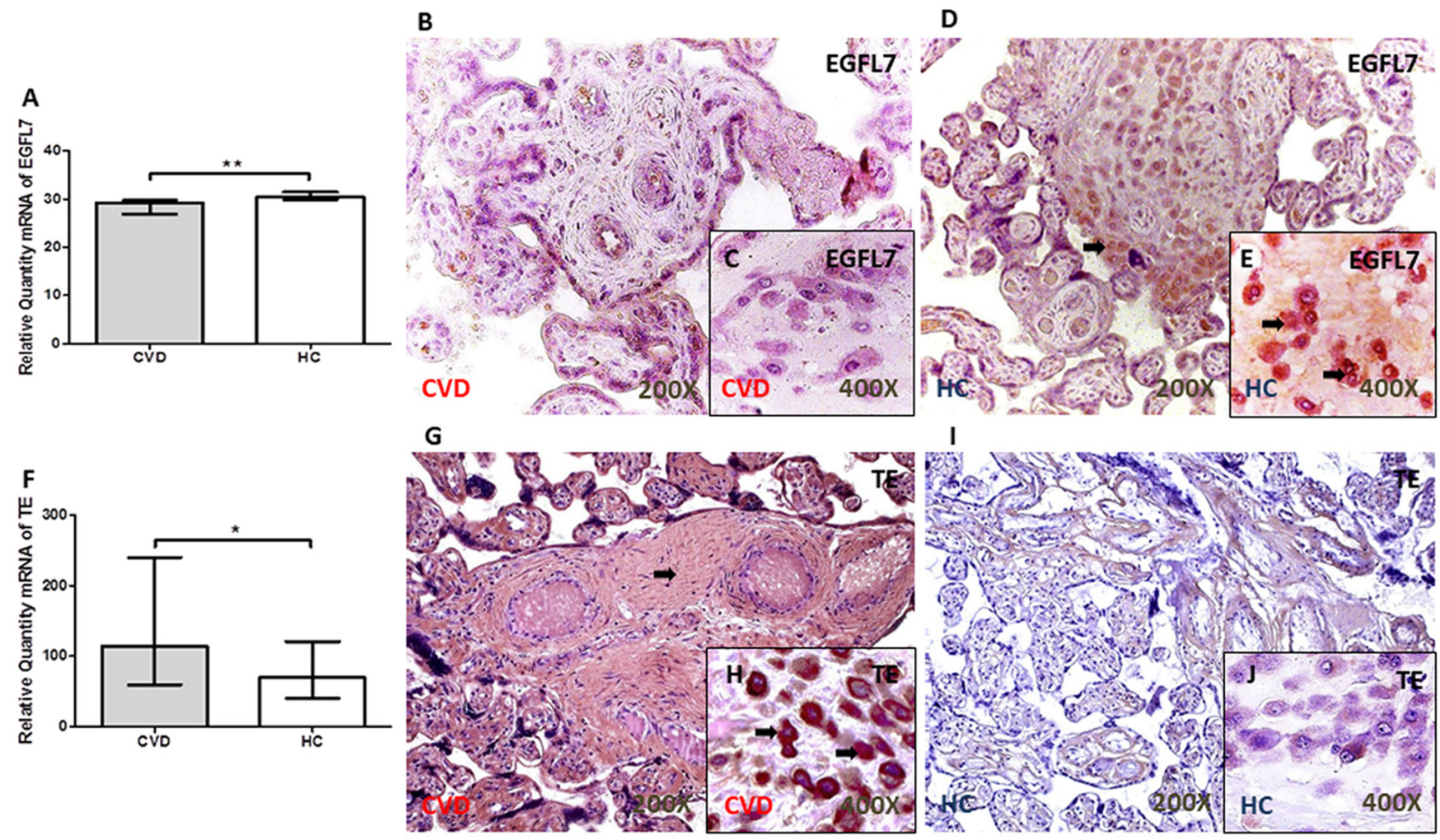

Figure 1. EGFL7 and Tropoelastin expression in the placental of women with CVD during pregnancy. (A) EGFL7 mRNA expression levels were determined using RT-qPCR and they were significantly higher in women from the HC group. Representative images of immunostaining for EGFL7 in the placental villi and decidual cells for (B and C) CVD and (D and E) HC using immunohistochemistry, respectively. (F) TE mRNA expression levels were determined using RT-qPCR and they were significantly higher in women with CVD. Representative images of immunostaining for TE in the placental villi and decidual cells for $(\mathrm{G}$ and $\mathrm{H}) \mathrm{CVD}$ and (I and J) HC using immunohistochemistry, respectively. The arrow indicates positive protein expression. Data are expressed as the median and interquartile range. ${ }^{*} \mathrm{P}<0.05 .{ }^{* *} \mathrm{P}<0.01$. EGFL7, EGF-like domain-containing protein 7 ; CVD, chronic venous disease; HC, healthy controls; TE, tropoelastin; RT-qPCR, reverse transcription-quantitative PCR.

\section{Results}

EGFL7 is expressed at low levels in the placental villi of women with CVD during pregnancy. There was a significant decrease in the EGFL7 gene expression level in the placental villi of women with CVD during pregnancy $(\mathrm{P}=0.0012$; Fig. 1A). The results from the protein expression levels showed that the IRS score was significantly lower in the placental villi from the CVD group [CVD, 0.00 (IQR, 0.00-1.25); HC, 1.00 (IQR, 0.00-2.00) P=0.0077; Fig. 1B and D]. Notably, there was a decrease in the percentage of decidual cells with EGFL7 protein expression [CVD, 15.50\% (IQR, 7.00-41.00\%); HC, $31.00 \%$ (IQR, 12.00-82.00\%); P=0.0059; Fig. 1C and E]. The arrows show the positive expression in the tissue.

TE expression level is significantly increased in the placenta of women with CVD during pregnancy. An increase in TE gene expression was observed in the placental villi of women with CVD during pregnancy compared with that in women from the $\mathrm{HC}$ group $(\mathrm{P}=0.0355$; Fig. $1 \mathrm{~F})$. The analysis of TE protein expression level using immunohistochemistry showed a significant increase in the IRS in patients with CVD, with intense staining throughout the ECM [CVD, 2.50 (IQR, 0.50-3.00); HC, 1.00 (IQR, 0.00-2.500); P=0.0003; Fig. $1 \mathrm{G}$ and I]. The percentage of decidual cells with TE protein expression level was significantly higher in the placenta of women with CVD during pregnancy [CVD, 52.00 (IQR, 16.00-96.00\%);
HC, 22.00 (IQR, 10.00-54.00\%); P=0.0005; Fig. 1H and J]. The arrows show the positive expression in the tissue.

$F B L N-4$ and FBN-1 expression level is increased in the placental villi of women with CVD during pregnancy. The FBLN-4 gene was significantly increased in the placental villi of women with CVD compared with that in women in the HC group ( $\mathrm{P}=0.0456$; Fig. $2 \mathrm{~A}$ ). An increase in FBN-1 gene expression was also observed in the CVD group [CVD, 76.26 (IQR, 35.39-259.70); HC, 55.39 (IQR, 8.81-156.02); $\mathrm{P}=0.0185$; Fig. 2D]. The arrows show the positive expression in the tissue.

The protein expression level of FBLN-4 did not differ significantly in the placental villi between the 2 groups [CVD, 0.87 (0.00-2.00); HC, 0.50 (IQR, 0.00-2.00); P=0.40], using the IRS score; however, FBLN-4 protein expression was observed around the large vessels in the placenta of women with CVD during pregnancy (Fig. 2B and C). By contrast, there was a significant increase in the IRS for FBN-1 in the placental villi of women with CVD during pregnancy [CVD, 1.25 (IQR, 0.50-3.00); HC, 1.00 (IQR, 0.00-3.00); $\mathrm{P}=0.0188$; Fig. $2 \mathrm{E}$ and $\mathrm{G}]$. The protein expression level of FBN-1 was particularly found around the large vessels in the placenta of patients with CVD (indicated by the arrow; Fig. 2E and F). No protein expression of FBLN-4 or FBN-1 was observed in decidual cells. The arrows show the positive expression in the tissue. 


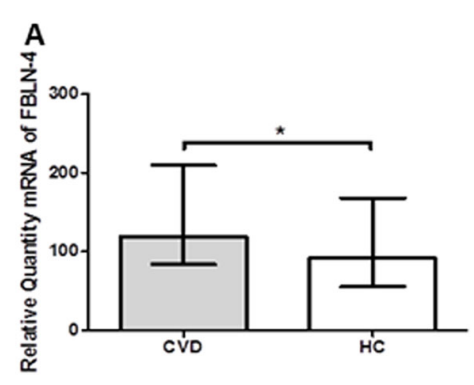

B
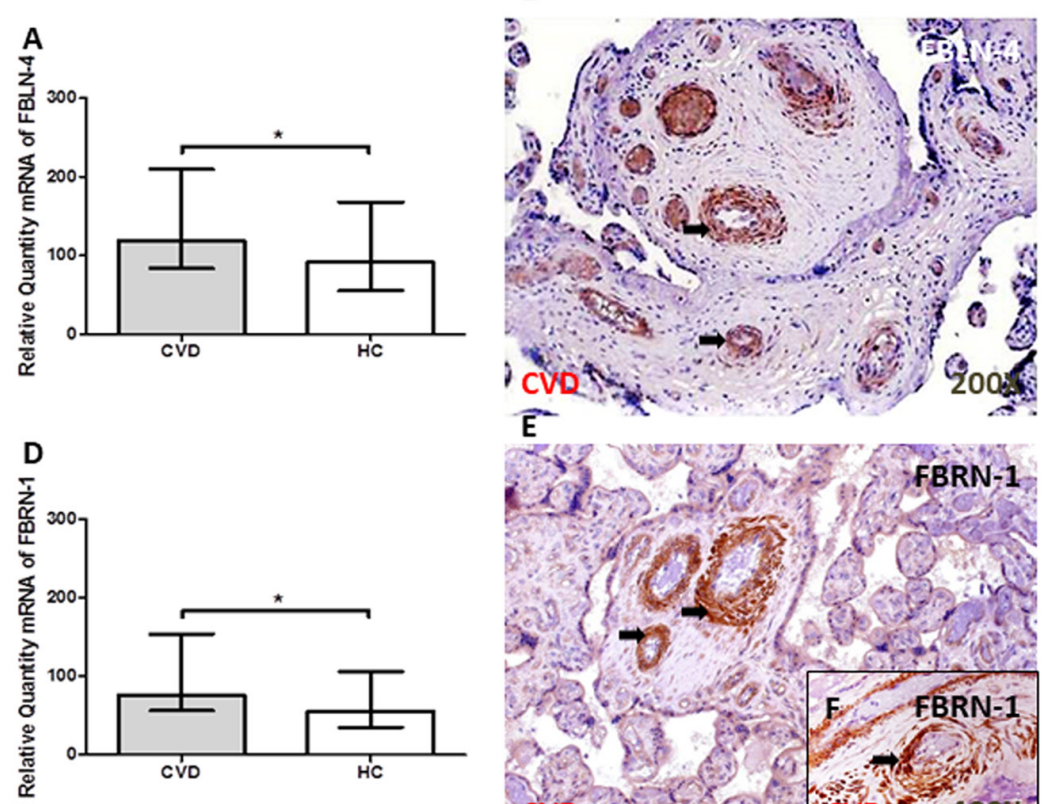

C
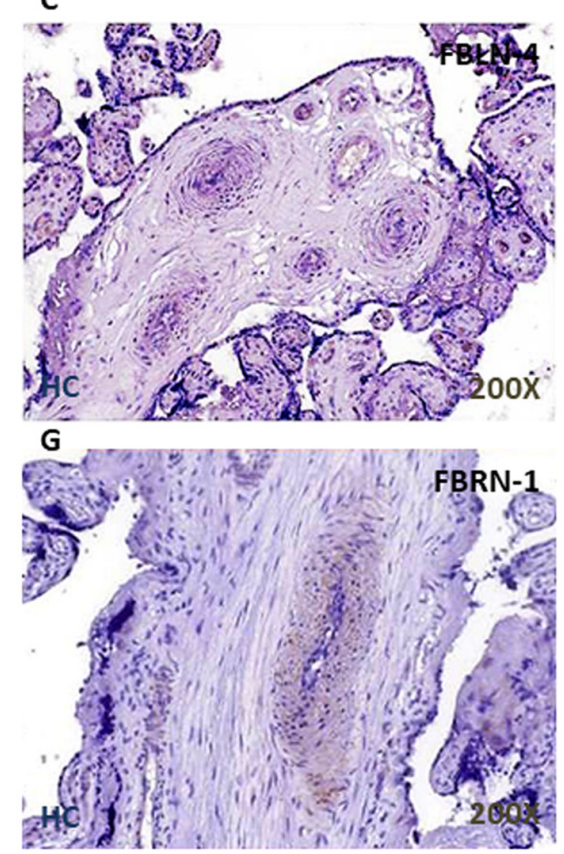

Figure 2. FBLN-4 and FBN-1 expression in the placenta of women with CVD during pregnancy. (A) FBLN-4 mRNA expression levels were determined using RT-qPCR and they were significantly higher in women with CVD. Representative images of immunostaining for FBLN-4 in the placental villi from women with (B) CVD and in the (C) HC group using immunohistochemistry. (D) FBN-1 mRNA expression levels was determined using RT-qPCR and they were significantly higher in women with CVD. Representative images of immunostaining for FBN-1 in the placental villi from women with (E and F) CVD and in the $(\mathrm{G}) \mathrm{HC}$ group using immunohistochemistry. The arrow indicates positive protein expression. Data are expressed as the median and interquartile range. ${ }^{*} \mathrm{P}<0.05$. FBLN-4, fibulin 4; FBN-1, fibrillin 1; CVD, chronic venous disease; HC, healthy controls; RT-qPCR, reverse transcription-quantitative PCR.

LOX and LOXL-1 expression level is increased in the placental villi of women with CVD during pregnancy. A significant increase in LOX gene expression level was observed in the placental villi of women with CVD during pregnancy $[\mathrm{P}=0.0344$; Fig. 3A]. Similarly, the gene expression level of LOXL-1 was significantly higher in the placental villi from women with CVD [CVD, 96.63 (IQR, 41.99-321.38); HC, 68.26 (IQR, 27.30-247.54); P=0.0390; Fig. 3F).

The results from protein expression showed an increase in the IRS in the placental villi of women with CVD during pregnancy for LOX [CVD, 2.00 (IQR, 0.50-3.00); HC, 1.00 (IQR, 0.00-2.50); $\mathrm{P}=0.0036$ ] (Fig. 3B and D) and LOXL-1 [CVD, 2.50 (IQR, 2.00-3.00); HC, 1.00 (IQR, 0.00-2.50); $\mathrm{P}<0.0001]$ (Fig. 3.G and I). In addition, an increase in the protein expression level of LOX [CVD, 50.50\% (IQR, 21.00-85.00\%); HC, 21.00 (IQR, 9.00-41.00\%); P<0.0001] (Fig. 3C and E) and LOXL-1 [CVD, 18.00\% (IQR, 7.00-45.00\%); $\mathrm{HC}, 9.00 \%$ (6.00-21.00\%), $\mathrm{P}=0.0021$ ] (Fig. $3 \mathrm{H}$ and $\mathrm{J}$ ) was observed in the placental decidual cells (Fig. 3.C and $\mathrm{H}$ ) of women with CVD during pregnancy. The arrows show the positive expression in the tissue.

Significant increases in the number of elastic fibers in the placental villi from women with CVD during pregnancy. Orcein staining revealed the presence of a significant increase in the elastic fibers in the placenta from women with CVD during pregnancy $(\mathrm{P}=0.0110$; Fig. 4A), particularly in the placental villi (Fig. 4B) and around the decidual cells (Fig. 4C). In the HC group, the staining was not as intense in either the placental villi (Fig. 4D) or in the decidual cells (Fig. 4E).

\section{Discussion}

CVD is a frequent complication of pregnancy, that can alter placental homeostasis and have important repercussions on the health of the mother and the fetus $(3,19)$. The ECM is a dynamic network of macromolecules, that is constantly being remodeled $(29,30)$. The ECM plays a key role in the correct development, implantation and separation of the placenta, in addition to responding to hormonal changes, that occur during pregnancy, particularly from progesterone $(31,32)$. In patients with CVD, the results from previous studies showed that there was a redistribution of these hormonal receptors in the venous tissue, affecting vascular homeostasis and the ECM $(33,34)$. The expression levels of the different ECM components of elastic fibers were elevated in the placenta of women with CVD during pregnancy, particularly the collagen fibers and metalloproteins in the context of different hypertensive disorders, such as preeclampsia (35).

The mechanical properties of tissues are fundamental to their proper functioning, and the components of the ECM are responsible for these mechanical properties (30). Notably, the rigidity/elasticity of the cellular environment is key for the maintenance of tissue homeostasis and changes in elasticity can affect the progression of the disease in general (36). Ortega et al (17) demonstrated that there was a change in the mRNA and protein expression profile of collagen fibers in the placental villi of women with CVD during pregnancy, particularly with type III collagen and in the collagen I/collagen III ratio, and there was a significant increase in MMP-9 gene and protein expression levels in the placental villi and decidual cells. However, the condition of the elastic fibers in the placenta 

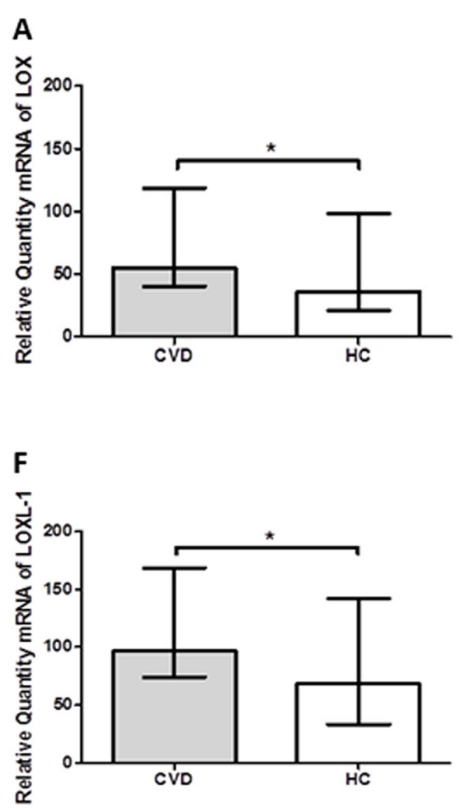

B

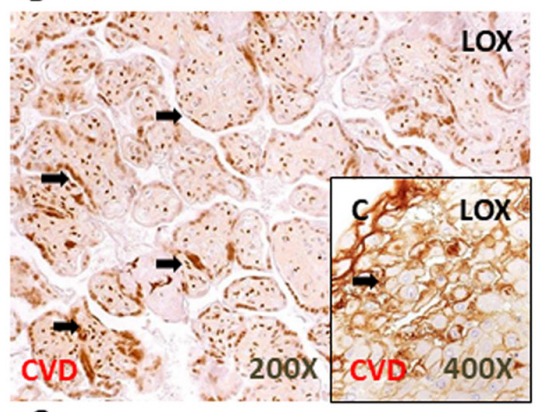

G

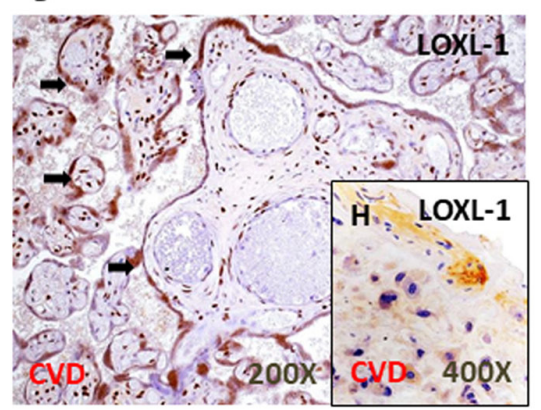

D

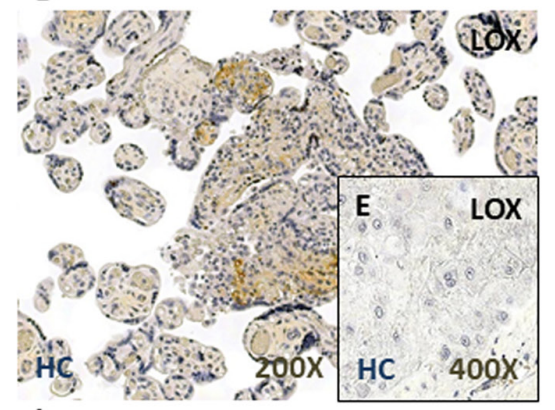

I

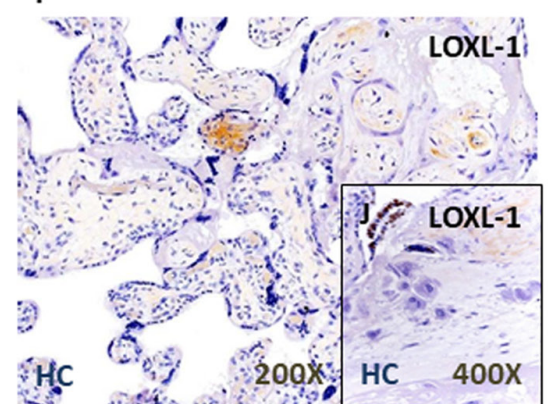

Figure 3. LOX and LOXL-1 expression in the placental of women with CVD during pregnancy. (A) LOX mRNA expression levels were determined using RT-qPCR and they were significantly higher in women with CVD. Representative images of immunostaining for LOX in the placental villi and decidual cells in women with (B and C) CVD and in the (D and E) HC group using immunohistochemistry. (F) LOXL-1 mRNA expression levels were determined using RT-qPCR and they were significantly higher in women with CVD. Representative images of immunostaining for LOXL-1 in the placental villi and decidual cells from women with (G and H) CVD and in the (I and J) HC group using immunohistochemistry. The arrow indicates positive protein expression. Data are expressed as the median with interquartile range. "P<0.05. LOX, lysyl oxidase; LOXL-1, lysyl oxidase-like 1; CVD, chronic venous disease; HC, healthy controls; RT-qPCR, reverse transcription-quantitative PCR.
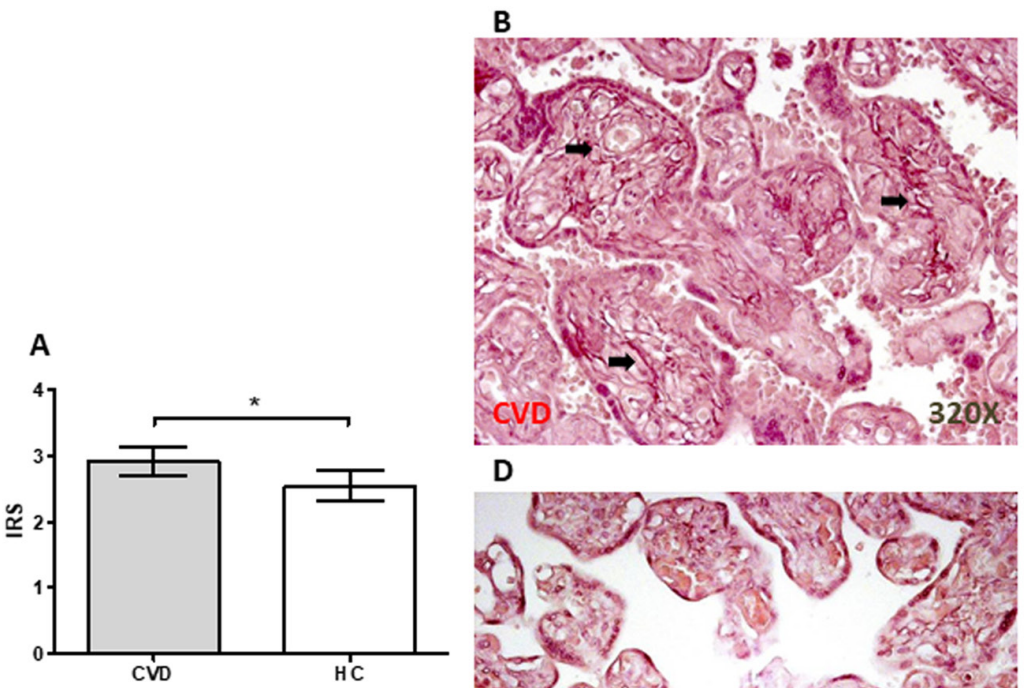

D

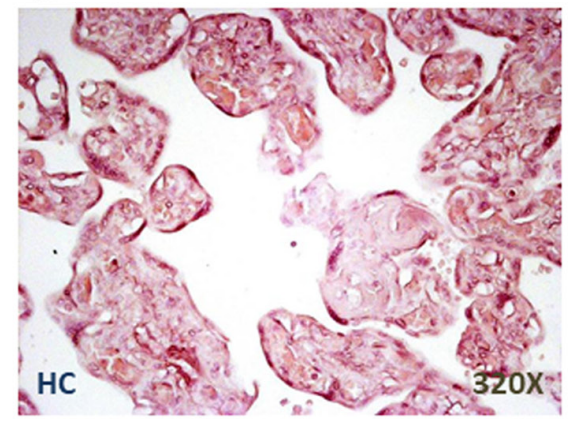

C

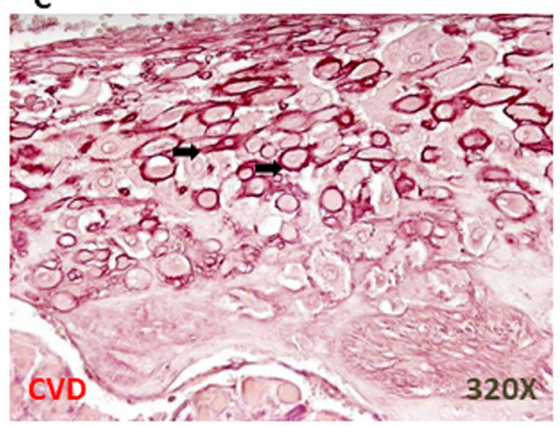

E

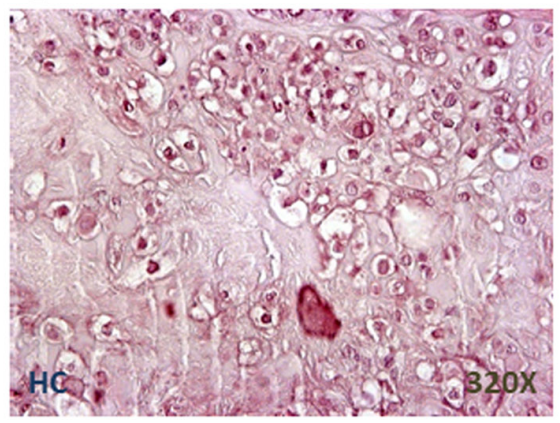

Figure 4. Elastic fibers in the placental villi from women with CVD during pregnancy. (A) IRS for orcein stain. Representative images showing the orcein staining in the placental villi and decidual cells from women with (B and C) CVD and from those in the (D and E) HC group, respectively. Data are expressed as the median and interquartile range; ${ }^{*} \mathrm{P}<0.05$. CVD, chronic venous disease; $\mathrm{HC}$, healthy controls; IRS, immunoreactive score.

of women with CVD has not been fully elucidated yet. These fibers are essential for providing tissues with elastic properties, as well as for regulating the bioavailability of components, such as TGF- $\beta$, and alterations in this system arise in a wide variety of inherited or acquired pathologies, such as Marfan or cancer $(37,38)$. It is important to investigate the elasticity 
of the placenta and to develop techniques to evaluate its state under multiple conditions (39). The results from the present study showed that there was variation in the expression level of TE, as well as in the different components of ECM, such as FBLN-4, FBN-1 and the lysyl oxidase family (LOX and LOXL-1).

Lysyl oxidases are a set of fundamental enzymes found in a wide variety of tissues, including the placenta, where their importance in the regulation of the composition of the ECM has been previously described (40). In prelabor rupture of fetal membranes, increased levels of these enzymes have been associated with changes in the cell cycle and in promoting oxidative stress in some placental complications (41). Recently, an association was found between CVD during pregnancy and an increase in oxidative stress markers in these placentas (11). The increased expression of these enzymes in patients with CVD suggests that lysyl oxidases could play an important role in CVD. These enzymes play roles in the crosslinking of collagen fibers (36) and in the regulation and homeostasis of elastic fibers (42). Higher expression in the regulation of both components have been reported in the vascular tissues of some placental complications, such as fetal growth restriction (43). LOX and LOXL-1 were found to interact directly with TE, promoting the formation of mature elastic fibers (44). TE is a fundamental component of elastic fibers and is a precursor to elastin, which participates in cell attachment; any alteration in its expression could; therefore, be associated with the requirement to meet the demands of a hypertensive event $(45,46)$. In this regard, one of the limitations of the present study was that LOX activity was not measured, as an alternative method of measuring the function of LOX.

FBN-1 expression level was increased in the placental villi of women with CVD during pregnancy, in the present study. FBN-1 is a widely distributed protein in the stroma of placental villi and is detected mainly as a thin layer, that encapsulates decidual cells, and occurs in the form of fibrils, that are in contact with these cells $(47,48)$. The expression level of FBN-1 has been associated with conferring a certain stiffness to more elastic tissues (49). Costa et al (50) showed that this protein is part of an important myofibroelastic system in the functionality of the placental terminal villi and was upregulated in patients with preeclampsia or systemic lupus erythematosus. Recently, Abbas et al (51) demonstrated that this molecule was also expressed in extravillous trophoblasts, conferring greater tissue rigidity. The present study showed the increase of FBN-1 expression in the placental tissue of women with CVD during pregnancy. In addition, it has been shown that FBN-1 binds calcium molecules in the ECM of different tissues, such as vascular structures (52). The increase in mRNA expression level and IRS of FBN-1 was confirmed in the present study. A previous study demonstrated an increase in the calcifications of the placental villi in pregnant women with CVD (18). Thus, the importance of FBN-1 in responding to the changes in the placenta of women with CVD during pregnancy should be considered.

FBLN-4 can significantly regulate the homeostasis of elastic fibers (53). Notably, FBLN-4 is fundamental to the process of sequential elastogenesis (54). The results from the present study showed that there was an increase in this component, showing that it is involved in the elastogenesis process in the placentas of women with CVD. The effect of deletions mutations in this component has been described in some pathologies, such as aneurysms (55); however, the effect of overexpression in different pathologies is still under investigation, such as placental complications. In addition, FBLN-4 has important functions beyond the regulation of elastic fibers; therefore, an increase in its gene and protein expression could be associated with different altered processes in placental tissue; however, this hypothesis requires confirmation (53).

The results from the present study demonstrated an association between CVD during pregnancy and the process of elastogenesis in the placental villi. Proteins that may play a role in elastogenesis were investigated, such as EGFL7, and the results showed a decrease in the gene and protein expression level of EGFL7 in the placental villi of women with CVD. EGFL7 is an important component in endothelial cells during their development (56). Lacko et al (57) showed that EGFL7 activity has repercussions on the endothelial homeostasis of the maternal and fetal vasculature, indicating the importance of this protein in placental development and that its mRNA expression was reduced in preeclampsia. Lelièvre et al (15) showed that EGFL7 interacted with the catalytic subunit of lysyl oxidases in the vascular wall, preventing the crosslinking of TE molecules and inhibiting the formation of elastin polymers; thus, regulating the elastogenesis process. The results from the present study indicated that it was possible to observe a gene and protein expression between the downregulation of EGFL7 by immunohistochemistry and RT-qPCR and a change in the expression of elastic fiber promoters in the placental tissue of women with CVD.

EGFL7 also plays a key role in trophoblasts, particularly during the invasion and migration processes of these cells (58). In an EGFL7 knockout mice model, alterations in the morphogenesis of the chorionic villi were observed, as were changes in vascular patterns, indicating the possible involvement of this knockout in intrauterine growth restriction (59). The results from the present study further identified the changes that occur in these processes in the placental villi. Shrestha et al (60) showed that an increase in body weight during pregnancy epigenetically regulated EGFL7 expression. A limitation to the present study was that it only included in vitro results. Future studies should be aimed at verifying the behavior of different cell types of placental villi and confirming the viability of the ECM following EGFL7 inhibition, as well as phenotyping decidual cells to understand their role in vascular diseases.

Previous studies have observed how the placental villi of pregnant women with CVD had a significant increase in hypoxia-inducible factors, proteins related to apoptosis and oxidative stress $(3,11)$. In addition, a significant increase in the number of placental villi was also observed in relation to CVD $(3,11,19)$. Notably, it was found that there was a decrease in the fetal venous $\mathrm{pH}$ at delivery (11), suggesting that venous hypertension, as a result of CVD, triggers an adaptive process, which enables the placental villi to combat the developing hypoxia in the intervillous chamber. To the best of our knowledge, the results from the present study showed an association between the expression level of proteins related to elastogenesis and gestational CVD for the first time. 


\section{Acknowledgements}

Not applicable.

\section{Funding}

The study (FIS-PI18/00912) was supported by the Instituto de Salud Carlos III (grant no. Estatal de I + D+I 2013-2016) and co-financed by the European Development Regional Fund 'A way to achieve Europe' and B2017/BMD-3804 MITIC-CM (Comunidad de Madrid).

\section{Availability of data and materials}

The datasets used and/or analyzed during the current study are available from the corresponding author on reasonable request.

\section{Authors' contributions}

$\mathrm{NGH}, \mathrm{JB}$ and MAM contributed to the design of the study, acquired funding and supervised the study. MAO, AA, SC and FS was involved in the administration of the study. MAO, MAS, SC, AA, OFM, JADLL, MAAM, CB and FS performed the experiments. NGH, JB, MAM and MAO validated and curated the data in the study. SC and JB confirm the authenticity of all the raw data All authors have read and approved the final version of the manuscript.

\section{Ethics approval and consent to participate}

This study was approved by the Clinical Research Ethics Committee of the Central University Hospital of Defense-UAH (37/17). The patients/participants provided their written informed consent to participate in this study.

\section{Patient consent for publication}

Not applicable.

\section{Competing interests}

The authors declare that they have no competing interests.

\section{References}

1. Ouzounian JG and Elkayam U: Physiologic changes during normal pregnancy and delivery. Cardiol Clin 30: 317-329, 2012.

2. Troiano NH: Physiologic and hemodynamic changes during pregnancy. AACN Adv Crit Care 29: 273-283, 2018.

3. García-Honduvilla N, Ortega MA, Asúnsolo Á Álvarez-Rocha MJ, Romero B, De León-Luis J, Álvarez-Mon M and Buján J: Placentas from women with pregnancy-associated venous insufficiency show villi damage with evidence of hypoxic cellular stress. Hum Pathol 77: 45-53, 2018.

4. Saliba Júnior OA, Rollo HA, Saliba O and Sobreira ML: Graduated compression stockings effects on chronic venous disease signs and symptoms during pregnancy. Phlebology 35: $46-55,2020$

5. Ropacka-Lesiak M, Jarosław $K$ and Bręborowicz G: Pregnancy-dependent blood flow velocity changes in lower extremities veins in venous insufficiency. Ginekol Pol 86: 659-665, 2015.

6. Iupatov EI, Ignat'ev IM and Fomina EE: Ultrasonographic examination of major veins of lower limbs and pelvic veins in pregnant women. Angiol Sosud Khir 24: 70-75, 2018 (In Russian).
7. Asbeutah AM, Al-Azemi M, Al-Sarhan S, Almajran A and Asfar SK: Changes in the diameter and valve closure time of leg veins in primigravida women during pregnancy. J Vasc Surg Venous Lymphat Disord 3: 147-153, 2015.

8. Fanfera FJ and Palmer LH: Pregnancy and varicose veins. Arch Surg 96: 33-35, 1968.

9. Davies AH: The seriousness of chronic venous disease: A review of Real-World evidence. Adv Ther 36 (Suppl 1): S5-S12, 2019.

10. El-Sayed AAF: Preeclampsia: A review of the pathogenesis and possible management strategies based on its pathophysiological derangements. Taiwan J Obstet Gynecol 56: 593-598, 2017.

11. Ortega MA, Romero B, Asúnsolo Á, Martínez-Vivero C, Sainz F, Bravo C, De León-Luis J, Álvarez-Mon M, Buján J and García-Honduvilla N: Pregnancy-associated venous insufficiency course with placental and systemic oxidative stress. J Cell Mol Med 24: 4157-4170, 2020.

12. Smith SD, Choudhury RH, Matos P, Horn JA, Lye SJ, Dunk CE, Aplin JD, Jones RL and Harris LK: Changes in vascular extracellular matrix composition during decidual spiral arteriole remodeling in early human pregnancy. Histol Histopathol 31: 557-571, 2016.

13. Gauster M, Berghold VM, Moser G, Orendi K, Siwetz M and Huppertz B: Fibulin-5 expression in the human placenta. Histochem Cell Biol 135: 203-213, 2011.

14. Schmidt M, De Mazière A, Smyczek T, Gray A, Parker L, Filvaroff E, French D, van Dijk S, Klumperman J and Ye W: The role of Egfl7 in vascular morphogenesis. Novartis Found Symp 283: 18-28, 2007.

15. Lelièvre E, Hinek A, Lupu F, Buquet C, Soncin F and Mattot V: VE-statin/egfl7 regulates vascular elastogenesis by interacting with lysyl oxidases. EMBO J 27: 1658-1670, 2008.

16. Rahat B, Sharma R, Bagga R, Hamid A and Kaur J: Imbalance between matrix metalloproteinases and their tissue inhibitors in preeclampsia and gestational trophoblastic diseases. Reproduction 152: 11-22, 2016.

17. Ortega MA, Asúnsolo Á, Álvarez-Rocha MJ, Romero B DeLeón-Luis J,Álvarez-Mon M, Buján J and García-Honduvilla N: Remodelling of collagen fibres in the placentas of women with venous insufficiency during pregnancy. Histol Histopathol 33: 567-576, 2018.

18. Ortega MA, Saez MÁ, Asúnsolo Á, Romero B, Bravo C, Coca S, Sainz F, Álvarez-Mon M, Buján J and García-Honduvilla N: Upregulation of VEGF and PEDF in placentas of women with lower extremity venous insufficiency during pregnancy and its implication in villous calcification. Biomed Res Int 2019: 5320902, 2019

19. Ortega MA, Saez MA, Fraile-Martínez O, Asúnsolo Á, Pekarek L, Bravo C, Coca S, Sainz F, Mon MÁ, Buján J and García-Honduvilla N: Increased angiogenesis and lymphangiogenesis in the placental villi of women with chronic venous disease during pregnancy. Int J Mol Sci 21: 2487, 2020.

20. Lurie F, Passman M, Meisner M, Dalsing M, Masuda E, Welch H, Bush RL, Blebea J, Carpentier PH, De Maeseneer M, et al: The 2020 update of the CEAP classification system and reporting standards. J Vasc Surg Venous Lymphat Disord 8: 342-352, 2020.

21. Ortega MA, Asúnsolo Á, Leal J, Romero B, Alvarez-Rocha MJ, Sainz F, Álvarez-Mon M, Buján J and García-Honduvilla N: Implication of the PI3K/Akt/mTOR Pathway in the process of incompetent valves in patients with chronic venous insufficiency and the relationship with aging. Oxid Med Cell Longev 2018: 1495170, 2018.

22. Bustin SA, Benes V, Garson JA, Hellemans J, Huggett J, Kubista M, Mueller R, Nolan T, Pfaffl MW, Shipley GL, et al: The MIQE Guidelines: Minimum information for publication of quantitative real-time PCR experiments. Clin Chem 55: 611-622, 2009.

23. Ye J, Coulouris G, Zaretskaya I, Cutcutache I, Rozen S and Madden TL: Primer-BLAST: A tool to design target-specific primers for polymerase chain reaction. BMC Bioinformatics 13: 134, 2012

24. Vallone PM and Butler JM: AutoDimer: A screening tool for primer-dimer and hairpin structures. Biotechniques 37: 226-231, 2004.

25. Livak KJ and Schmittgen TD: Analysis of relative gene expression data using real-time quantitative PCR and the 2(-Delta Delta C(T)) Method. Methods 25: 402-408, 2001.

26. Ortega MA, Romero B, Asúnsolo Á, Sola M, Álavrez-Rocha MJ, Sainz F, Álavrez-Mon M, Buján J and García-Honduvilla N: Patients with incompetent valves in chronic venous insufficiency show increased systematic lipid peroxidation and cellular oxidative stress markers. Oxid Med Cell Longev 2019: 5164576, 2019. 
27. Remmele W and Schicketanz KH: Immunohistochemical determination of estrogen and progesterone receptor content in human breast cancer: Computer-assisted image analysis (QIC score) vs. subjective grading (IRS). Pathol Res Pract 189: 862-866, 1993.

28. Cristóbal L, Ortega MA, Asúnsolo Á, Romero B, Álvarez-Mon M, Buján J, Maldonado AA and García-Honduvilla N: Human skin model for mimic dermal studies in pathology with a clinical implication in pressure ulcers. Histol Histopathol 33: 959-970, 2018.

29. Macura B and Śliwa L: Epigenetics in the placenta, the current knowledge and future clinical perspectives. Przegl Lek 72 : 673-676, 2015

30. Chen Y, Peng W, Raffetto JD and Khalil RA: Matrix metalloproteinases in remodeling of lower extremity veins and chronic venous disease. Prog Mol Biol Transl Sci 147: 267-299, 2017.

31. Chabbert-Buffet N, Meduri G, Bouchard P and Spitz IM: Selective progesterone receptor modulators and progesterone antagonists: Mechanisms of action and clinical applications. Hum Reprod Update 11: 293-307, 2005.

32. Franczyk M, Lopucki M, Stachowicz N, Morawska D and Kankofer M: Extracellular matrix proteins in healthy and retained placentas, comparing hemochorial and synepitheliochorial placentas. Placenta 50: 19-24, 2017.

33. García-Honduvilla N, Asúnsolo Á, Ortega MA, Sainz F, Leal J, Lopez-Hervas P, Pascual G and Buján J: Increase and redistribution of sex hormone receptors in premenopausal women are associated with varicose vein remodelling. Oxid Med Cell Longev 2018: 3974026, 2018

34. Ortega MA, Asúnsolo Á, Romero B, Álvarez-Rocha MJ, Sainz F, Leal J, Álvarez-Mon M, Buján J and García-Honduvilla N: Unravelling the role of MAPKs (ERK1/2) in venous reflux in patients with chronic venous disorder. Cells Tissues Organs 206 272-282, 2018

35. Ren Z, Cui N, Zhu M and Khalil RA: Placental growth factor reverses decreased vascular and uteroplacental MMP-2 and MMP-9 and increased MMP-1 and MMP-7 and collagen types I and IV in hypertensive pregnancy. Am J Physiol Heart Circ Physiol 315: H33-H47, 2018.

36. Handorf AM, Zhou Y, Halanski MA and Li WJ: Tissue stiffness dictates development, homeostasis, and disease progression. Organogenesis 11: 1-15, 2015.

37. Baldwin AK, Simpson A, Steer R, Cain SA and Kielty CM: Elastic fibres in health and disease. Expert Rev Mol Med 15: e8, 2013.

38. Ortega MA, Romero B, Asúnsolo Á, Sainz F, Martinez-Vivero C, Álvarez-Mon M, Buján J and García-Honduvilla N: Behavior of smooth muscle cells under hypoxic conditions: Possible implications on the varicose vein endothelium. Biomed Res Int 2018 : 7156150,2018

39. Simon EG, Callé S, Perrotin F and Remenieras JP: Measurement of shear wave speed dispersion in the placenta by transient elastography: A preliminary ex vivo study. PLoS One 13: e0194309, 2018 .

40. Hein S, Yamamoto SY, Okazaki K, Jourdan-LeSaux C, Csiszar K and Bryant-Greenwood GD: Lysyl oxidases: Expression in the fetal membranes and placenta. Placenta 22: 49-57, 2001

41. Polettini J, Silva MG, Kacerovsky M, Syed TA, Saade GR and Menon R: Screening of lysyl oxidase (LOX) and lysyl oxidase like (LOXL) enzyme expression and activity in preterm prelabor rupture of fetal membranes. J Perinat Med 44: 99-109, 2016.

42. Liu X, Zhao Y, Gao J, Pawlyk B, Starcher B, Spencer JA, Yanagisawa $\mathrm{H}$, Zuo J and $\mathrm{Li}$ T: Elastic fiber homeostasis requires lysyl oxidase-like 1 protein. Nat Genet 36: 178-182, 2004

43. Saw SN, Tay JJH, Poh YW, Yang L, Tan WC, Tan LK, Clark A, Biswas A, Mattar CNZ and Yap CH: Altered placental chorionic arterial biomechanical properties during intrauterine growth restriction. Sci Rep 8: 16526, 2018.

44. Thomassin L, Werneck CC, Broekelmann TJ, Gleyzal C, Hornstra IK, Mecham RP and Sommer P: The Pro-regions of lysyl oxidase and lysyl oxidase-like 1 are required for deposition onto elastic fibers. J Biol Chem 280: 42848-42855, 2005.
45. Hieber AD, Corcino D, Motosue J, Sandberg LB, Roos PJ, Yu SY, Csiszar K, Kagan HM, Boyd CD and Bryant-Greenwood GD: Detection of elastin in the human fetal membranes: Proposed molecular basis for elasticity. Placenta 18: 301-312, 1997.

46. Baldock C, Oberhauser AF, Ma L, Lammie D, Siegler V, Mithieux SM, Tu Y, Chow JY, Suleman F, Malfois M, et al: Shape of tropoelastin, the highly extensible protein that controls human tissue elasticity. Proc Natl Acad Sci USA 108: 4322-4327, 2011.

47. Jacobson SL, Kimberly D, Thornburg K and Maslen C: Localization of fibrillin-1 in the human term placenta. J Soc Gynecol Investig 2: 686-690, 1995.

48. Fleming S and Bell SC: Localization of fibrillin-1 in human endometrium and decidua during the menstrual cycle and pregnancy. Hum Reprod 12: 2051-2056, 1997.

49. Sherratt MJ, Baldock C, Louise Haston JL, Holmes DF, Jones CJ, Shuttleworth CA, Wess TJ and Kielty CM: Fibrillin microfibrils are stiff reinforcing fibres in compliant tissues. J Mol Biol 332: 183-193, 2003.

50. Costa AM, Maximiano EB, Avvad-Portari E, Jésus NR, Levy RA and Porto LC: Contractile cells and fibrillin-1 distribution is disturbed in terminal villi of placentae from patients with preeclampsia and systemic lupus erythematosus. Placenta 27: 234-243, 2006

51. Abbas Y, Carnicer-Lombarte A, Gardner L, Thomas J, Brosens JJ, Moffett A, Sharkey AM, Franze K, Burton GJ and Oyen ML: Tissue stiffness at the human maternal-fetal interface. Hum Reprod 34: 1999-2008, 2019.

52. Handford PA: Fibrillin-1, a calcium binding protein of extracellular matrix. Biochim Biophys Acta 1498: 84-90, 2000.

53. Papke CL and Yanagisawa H: Fibulin- 4 and fibulin-5 in elastogenesis and beyond: Insights from mouse and human studies. Matrix Biol 37: 142-149, 2014.

54. Kumra H, Nelea V, Hakami H, Pagliuzza A, Djokic J, Xu J, Yanagisawa $\mathrm{H}$ and Reinhardt DP: Fibulin-4 exerts a dual role in LTBP-4L-mediated matrix assembly and function. Proc Natl Acad Sci USA 116: 20428-20437, 2019.

55. Burger J, van Vliet N, van Heijningen P, Kumra H, Kremers GJ, Alves M, van Cappellen G, Yanagisawa H, Reinhardt DP, Kanaar R, et al: Fibulin-4 deficiency differentially affects cytoskeleton structure and dynamics as well as TGF $\beta$ signaling. Cell Signal 58: 65-78, 2019.

56. d'Audigier C, Susen S, Blandinieres A, Mattot V, Saubamea B, Rossi E, Nevo N, Lecourt S, Guerin CL, Dizier B, et al: Egfl7 represses the vasculogenic potential of human endothelial progenitor cells. Stem Cell Rev Rep 14: 82-91, 2018.

57. Lacko LA, Massimiani M, Sones JL, Hurtado R, Salvi S, Ferrazzani S, Davisson RL, Campagnolo L and Stuhlmann H: Novel expression of EGFL7 in placental trophoblast and endothelial cells and its implication in preeclampsia. Mech Dev 133: 163-176, 2014.

58. Massimiani M, Vecchione L, Piccirilli D, Spitalieri P, Amati F, Salvi S, Ferrazzani S, Stuhlmann H and Campagnolo L: Epidermal growth factor-like domain 7 promotes migration and invasion of human trophoblast cells through activation of MAPK, PI3K and NOTCH signaling pathways. Mol Hum Reprod 21: 435-451, 2015

59. Lacko LA, Hurtado R, Hinds S, Poulos MG, Butler JM and Stuhlmann H: Altered feto-placental vascularization, feto-placental malperfusion and fetal growth restriction in mice with Egfl7 loss of function. Development 144: 2469-2479, 2017.

60. Shrestha D, Ouidir M, Workalemahu T, Zeng X and Tekola-Ayele F: Placental DNA methylation changes associated with maternal prepregnancy BMI and gestational weight gain. Int J Obes (Lond) 44: 1406-1416, 2020.

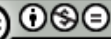

This work is licensed under a Creative Commons Attribution-NonCommercial-NoDerivatives 4.0 International (CC BY-NC-ND 4.0) License. 